\title{
Çanakkale İli Şeftali Bahçelerinde Farklı Mavi Renk Tuzaklarla Tropinota hirta (Poda) (Coleoptera: Cetoniidae) Ergin Uçuşunun Belirlenmesi
}

\author{
İbrahim Erbay Ali Özpınar \\ Çanakkale Onsekiz Mart Üniversitesi, Ziraat Fakültesi, Bitki Koruma Bölümü,17100 Çanakkale \\ *Sorumlu yazar: aozpinar@comu.edu.tr
}

Geliş Tarihi: 16.09.2019

Kabul Tarihi: 12.11.2019

\section{$\ddot{\mathbf{O z}}$}

Araştırma, Ezine (Çanakkale) ilçesi Akköy'de 5 dekarlık şeftali bahçesinde 2019 yılında yapılmıştır. Çalışmada, mavi rengin 5 farklı tonundaki leğen tuzakların $0 \mathrm{~cm}$ (yerde), $50 \mathrm{~cm}$ ve $110 \mathrm{~cm}$ yükseklikte Tropinota hirta (Poda) (Coleoptera: Cetoniidae) erginlerini yakalamadaki etkinliği incelenmiştir. Deneme tesadüf blokları deneme desenine göre 2 tekrarlı olarak kurulmuştur. Tuzaklar arasında 8 metre mesafe olacak şekilde iki ağacın ortasına 02.03.2019 tarihinde yerleştirilmiştir. Rüzgardan devrilmemeleri için tuzak leğenler yere ve sehpalara sabitlenerek, 1/3 oranında su ile doldurulmuş ve sabitleme iplerine ticari cezbediciler (TransAnethol + Cinnamyl Alcohol) bağlanmıştır. Yakalanan erginler 2 gün arayla tuzaklardaki sudan alınarak kaydedilmiş ve buharlaşan su tuzağa eklenmiştir. Örnekleme 03.05.2019 tarihine kadar devam etmiştir. Ayrıca 2 adet ticari tuzak kontrol amaçlı olarak ağaçlara asılmıştır. Tropinota hirta erginleri 04.03.2019 tarihinde henüz şeftali çiçek açmadan tüm tuzaklara yakalanmış ve en yüksek ergin sayısı çiçeklenmenin \%100'e ulaştığı 18 Mart 2019 tarihinde tespit edilmiştir. Örnekleme süresince $0 \mathrm{~cm}$ (yerde), $50 \mathrm{~cm}$ ve $110 \mathrm{~cm}$ yüksekliklerdeki tüm tuzaklara sırasıyla toplam 662, 972 ve 622 adet ergin yakalanmıştır. Çalışmada kullanılan H021, G021, H006, N015 ve Y157 kodlu mavi renk leğenlerde ise üç yükseklikte sırasıyla toplam 465, 363, 433, 628 ve 367 ergin kaydedilmiştir. İki adet ticari tuzakta ise toplam 131 adet ergin yakalanmıştır. Şeftali bahçesinde tüm tuzaklarda toplam 2387 adet $T$. hirta ergini kaydedilmiştir. Çalışmanın sonucunda en fazla ergin $50 \mathrm{~cm}$ yükseklikte ve N015 kodlu leğen tuzakta elde edilmiştir.

Anahtar Kelimeler: Çanakkale, Şeftali, Tropinota hirta, Mavi renk tuzaklar,

\section{Determination of Adults Flight of Tropinota hirta (Poda) (Coleoptera: Cetoniidae) with Different Hues of Blue Color Traps in Peach Orchards in Çanakkale Province \\ Abstract}

The research was conducted in a 0,5 ha peach orchard in Akköy, Ezine (Çanakkale) district in 2019 year. The aim of the study was to determine the effectiveness of traps colored in 5 different hues of blue, in catching the adults of Tropinota hirta (Poda) (Coleoptera: Cetoniidae) at $0 \mathrm{~cm}$ (ground level), $50 \mathrm{~cm}$ and $110 \mathrm{~cm}$ height. The experiment was conducted with randomized blocks experimental design with two repetitions. The traps were placed in the orchard on 01.03 .2019 between 2 trees on different lines a distance 8 meters them. Basins were fixed to the scaffolds with nails to prevent wind damage and then filled with water at $1 / 3$ ratio. Lures (Trans-Anethol+Cinnamyl Alcohol) were attached to fixing ropes. Adults captured in the traps were collected and evaporated water was filled to the specified level. Sampling of adults continued until 03.05.2019. Also, two commercial traps were used as control. First adults of Tropinota hirta were captured in the traps before the blooming period of peach trees on 04.03.2019 and the highest number of adults was found at $100 \%$ blooming on 18 March. During the sampling, a total of 662, 972 and 622 adults were captured in the traps at the heights of $0 \mathrm{~cm}, 50 \mathrm{~cm}$ and $110 \mathrm{~cm}$, respectively. The total number of adults captured at the traps with blue hues coded as H021, G021, H006, N015 and Y157 were 462, 363, 433, 628 and 367, respectively. Total number of adults in the commercial trap was 131. In the peach orchard, a total of 2387 T. hirta adults were recorded in all traps. At the end of the study, the highest number of adults was captured in the trap with N015 code at $50 \mathrm{~cm}$ height.

Keywords: Çanakkale, Peach, Tropinota hirta, Blue color traps

\section{Giriş}

Ülkemizde, Çanakkale ili meyve üretim potansiyeli bakımında önemli bir yere sahiptir. Değişik mikro klimaların varlığ 1 bu alanlarda farklı meyve türlerinin yetiştirilmesine olanak sunmaktadır. Çanakkale ili tarım alanının \%20'si meyveliklerden oluşmakta ve bu alanların \%11,2'sinde şeftali ile nektarin üretilmektedir (TUIK, 2018). Çanakkale, Türkiye şeftali ve nektarin üretiminin \%17,3 ile \%25,1’ni gerçekleştirerek birinci sırada yer almıştır. 
Meyve yetiştiriciliği, yöreye uyum sağlayan bazı polifag zararlılar için, yıl boyunca uygun besin kaynağını oluşturmaktadır. Çanakkale'de şeftali başta olmak üzere kiraz, elma, kayısı ve erik gibi meyvelerde zararlı olan Grapholita molesta (Busk)'nın mücadelesine esas olabilecek bazı biyolojik parametreler belirlenmiştir (Özpınar ve ark.,2012; Özpınar ve ark. 2014; Şahin, 2018). Yine şeftalide Anarsia lineatella Zeller ile mücadelede şaşırtma tekniğinin kullanım olanakları araştırılmıştır (Özpınar ve Uçar, 2018). Benzer şekilde sert ve yumuşak çekirdekli meyve zararlısı Archips türleri bu kapsamda ele alınmıştır (Ercan ve Özpınar, 2014). Makalelerin bir bölümünde Epicometis hirta olarak bilinen polifag zararlılardan Tropinota hirta (Poda 1761), (Coleoptera: Cetoniidae)'nın (Aydın ve Yaşar, 2019) Çanakkale ilinde kiraz alanlarındaki varlığı belirlenmiştir (Ertop ve Özpınar, 2011). Yine bu ilde yapılan başka bir çalışmada bu zararlının elma, erik, kayısı ve kiraz alanlarında mevcut olduğu ve şeftali alanlarında ise yüksek popülasyon yoğunluğuna ulaştığ tespit edilmiştir (Gezer ve Özpınar, 2015). T. hirta'nın erginleri meyve ağaçlarının çiçek ve polenlerini yiyerek zararlı olmaktadır (Özbek, 2008). Tokat yöresinde ise $T$. hirta erginlerinin armut bahçelerinde \%90-100 varan oranlarda zarar yaptığı tespit edilmiştir (Kara, 1992). Bulgaristan'da ise T. hirta'nın erginlerinin genç kiraz ağaçlarının çiçeklerinde yaklaşı \% $\%$ 'e varan oranlarda zarar meydana getirdiği belirlenmiştir (Kutinkova ve Andreev, 2004).

Meyvelerin çiçeklenme döneminde tozlayıcı türlerin varlı̆̆ 1 nedeniyle bu zararlıya karşı kimyasal mücadele önerilmemekte olup, kültürel ve biyoteknik yöntemlerin kullanımı ve geliştirilmesi ön plana çıkmaktadır. Schmera ve ark. (2004) T. hirta'nın açık mavi renk tuzaklara yakalanmada 1:1 cinnamyl alkol ve trans-anethole karışımıyla başarının arttı̆̆ını, Aydın (2011) vişne bahçelerinde beyaz renkli tuzakların, çiçeklenme döneminde ve mavi renkli tuzakların ise çiçeklenme sonrasında daha fazla $T$. hirta ergini yakaladığını belirlemiştir. Sağdaş (2011) kiraz ve elma ağaçlarında, Yaşar ve Uysal (2013) ise erik ve kayısı ağaçlarında çekici eklenmiş mavi renk huni+su tuzakların ergin yakalamada başarılı olduğunu bildirmiştir. Arslan ve Aslan (2015) ise Kahramanmaraş ilinde badem bahçesinde $T$. hirta 'yı yakalamada cezbedici ilave edilmiş huni tipi tuzakların başarılı olduğunu tespit etmiştir. Oltean ve ark. (2015) T. hirta'yı yakalamak için kullandıkları üç farklı tuzak içinde mavi renkli huni tuzakların, yer ve ağaca asılan beyaz renkli tuzaklardan daha fazla ergin bireyi yakaladığını bildirmiştir. Çanakkale ilinde ise cezbedici ilave edilmiş mavi renkli leğen tuzakların levha ve huni tuzaklara göre daha fazla $T$. hirta ergini yakaladığ 1 tespit edilmiştir (Gezer ve Özpınar, 2015). Isparta'da kiraz bahçesinde mavi rengin 5 farklı tonunda "light steel blue l" huni tuzakla en fazla $E$. hirta erginin yakalandığını (Yaşar ve ark (2013) ve bu tuzağın en iyi sonucu 1,5 m yükseklikte sağladığı bildirilmiştir (Güvenç ve Yaşar, 2014).

Bu çalışmalar 1şı̆̆ında; Çanakkale ilinde şeftali bahçesinde çiçeklenme döneminde mavi rengin 5 farklı tonundaki leğen tuzakların $0 \mathrm{~cm}$ (yerde), 50 ve $110 \mathrm{~cm}$ yükseklikte $T$. hirta erginlerini yakalamadaki etkisi karşılaştırılmıştır.

\section{Materyal ve Yöntem}

Çalışma, Gezer ve Özpınar (2015)'a göre en fazla T. hirta erginin yakalandı̆̆ 1 Ezine (Çanakkale) ilçesi Akköy'de üreticiye ait 5 dekarlık şeftali bahçesinde (Şekil 1) 01.03.201903.05.2019 tarihlerinde yürütülmüştür. Deneme bahçesi, çalı ve ağaç formundaki farklı bitki örtüsünün yer aldığı, su varlığının devamlı olduğu, dere kenarında ve kuzey rüzgârlarına kapalı mera alanın yakınında yer almıştır. Glohaven şeftali çeşidinin ağırlıkta olduğu bahçede ağaçların tomurcukları 20.02.2019 tarihinde kabarmaya başlamış ve ilk çiçekler 06.03.2019 tarihinde görülmüş olup, tam çiçeklenme ise 18-20 Mart2019 tarihlerinde kaydedilmiştir.

T. hirta erginlerini yakalamada kullanılan $36 \mathrm{~cm}$ genişliğinde, $27 \mathrm{~cm}$ çapında ve $14 \mathrm{~cm}$ derinliğindeki şeffaf leğenler, Yaşar ve ark. (2013)'na göre DYO firmasından sağlanan mavi rengin 5 farklı tonundaki boyalarla rulo firça yardımıyla boyanmış ve Colorimetre CR-400 ile leğenlerin ölçüm değerleri kaydedilmiştir (Çizelge 1).

Çizelge 1. Tropinota hirta ergin yakalamada Yaşar ve ark. (2013)'na göre kullanılan mavi renk boyalara uyarlanmış DYO boyanın renk kodları ve HUE değerleri

\begin{tabular}{|l|l|l|l|l|l|}
\hline Kod & Light steel blue 1 & Light blue & Deep sky blue & Light cyan & Deep royal blue \\
\hline Hexadecimal & \#C6DEFF & \#ADDFFF & \#3A9AD1 & \#E0FFFF & \#356AE8 \\
\hline RGB & $198,222,255$ & $173,223,255$ & $58,154,209$ & $224,255,255$ & $53,106,232$ \\
\hline DYO (HUE) & H021 $(278,46)$ & H006 $(263,65)$ & N015 $(272,39)$ & G021 $(269,32)$ & Y157 $(284,98)$ \\
\hline
\end{tabular}


Deneme tesadüf blokları deneme desenine göre 2 tekrarlı olarak planlanmıştır. Bahçenin kenar sıraları hariç tutularak leğen tuzaklar, sıra üzerinde 2 ağacın ortasına gelecek şekilde ve aralarında 8 metre mesafe bırakılarak 02.03.2019 tarihinde yerleştirilmiştir. Her uygulamanın yan yana gelmemesine özen gösterilmiş ve 5 farklı renkteki leğen tuzaklar yerde $(0 \mathrm{~cm}), 50 \mathrm{~cm}$ ve $110 \mathrm{~cm}$ olmak üzere 3 yükseklikte konumlandırılmıştır. Yerden 50 ve $110 \mathrm{~cm}$ yükseklikteki leğenler ahşap kazıklara monte edilmiş sehpalara konulmuştur. Sehpalara konulan leğenlerin etrafına çiviler çakılarak sabitlenmesi sağlanmıştır. Yerdeki leğenlerin de bu amaçla etrafına uygun uzunlukta 4 adet demir çubuk çakılmıştır. Leğenlerin rüzgârdan devrilmemesi için üstten ipler çapraz şekilde geçirilerek demir çubuklara ve çivilere bağlanmıştır. Bu sabitleme iplerine ise Kapar Organik Tarım Sanayi Ticaret Ltd. Şti.'nden temin edilmiş cezbediciler (100 mg Trans-Anethol+100 mg Cinnamyl Alcohol) suya değmeyecek şekilde monte edilmiştir. Leğenler $1 / 3$ oranında su ile doldurulmuş, yağmur ve benzeri durumlarda fazla suyun tahliye olması için üç tarafinda, böcek çıkışına izin vermeyecek büyüklükte su taşma delikleri açılmıştır. Kontrol amaçlı olarak da aynı firmanın cezbedicilerinin kullandığı 2 adet VARbk3 ticari tuzak ağaçlara asılarak kullanılmıştır (Şekil 2).

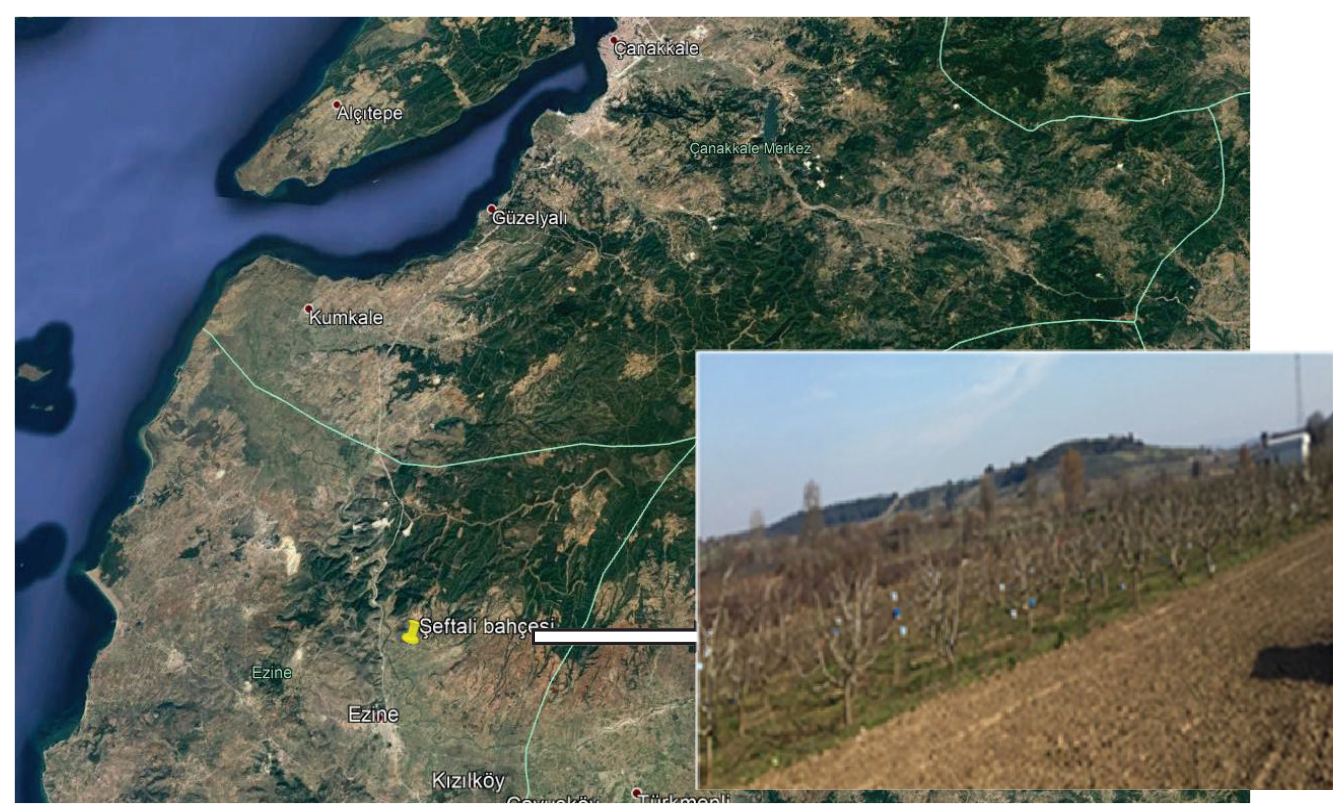

Şekil 1. Çalışmanın yapıldığı bahçenin konumu (3949'7.38"K; 26²0'39.34"D)

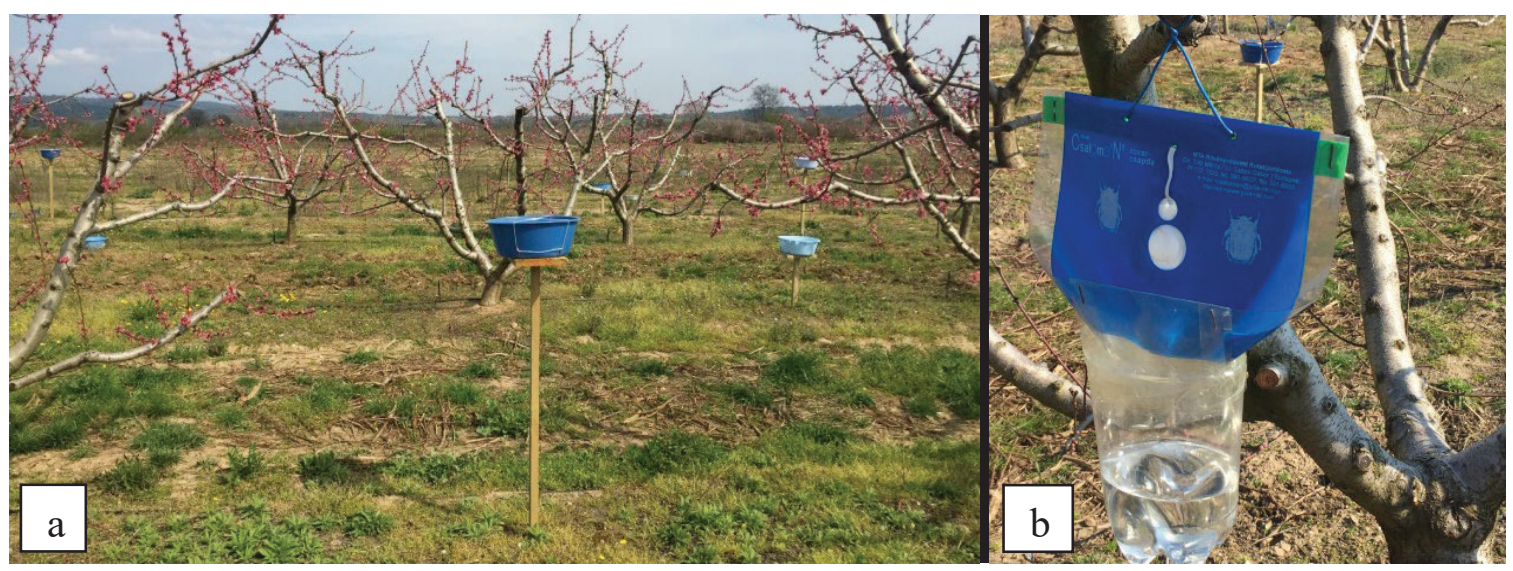

Şekil 2. Leğen ( a) ve ticari (b) tuzakların deneme bahçesine yerleştirilmiş hali

Denemede 01.03.2019 tarihinde her tekerrürde 15 adet olmak üzere 30 adet leğen tuzak ve 2 adet ticari tuzak kullanılmıştır. Leğen tuzaklardaki suya yakalanan erginler 2 gün arayla bir süzgeç 
yardımıyla sudan alınarak kaydedilmiş ve sayımlar 03.05.2019 tarihine kadar devam etmiştir. Örnekleme sırasında ağaçların çiçeklenme oranları (\%) kaydedilmiştir. Leğenlerin etrafindaki yabancıotlar temizlenmiş ve tuzaklarda buharlaşan su tamamlanmıştır. Günlük kaydedilen her tuzağa yakalanan ortalama ergin sayıları SPSS 23 istatistiksel paket programı (IBM, 2015) kullanılarak $\mathrm{P}<0,05$ önem seviyesine göre iki yönlü ANOVA testi uygulanarak karşılaştırılmıştır.

\section{Bulgular ve Tartışma}

\section{Farklı Tuzaklara Yakalanan Tropinota hirta Ergin Sayısı}

Ezine (Çanakkale) ilçesi Akköy'de her tekerrürde 15 adet olmak üzere toplam 30 adet leğen tuzak ile 2 adet de ticari tuzakta örnekleme süresince toplam 2387 adet $T$. hirta ergini kaydedilmiştir. Cezbediciler ilave edilerek kullanılan mavi rengin tonlarına ait H021, G021, H006, N015 ve Y157 kodlu tuzaklara (6 adet) üç farklı yükseklikte sırasıyla toplam 465, 363, 433, 628 ve 367 adet ergin yakalanmıştır. En fazla ergin 628 adet ile N015 kodlu tuzakta gerçekleşmiştir. Bu tuzağ 465 ve 433 adet ile H021 ve H006 kodlu tuzaklar izlemiştir. En düşük ergin sayısı 367 adet ile Y157 kodlu tuzakta kaydedilmiştir. Ayrıca, her tekerrürde birer ağaca asılan 2 adet ticari tuzakta tuzak başına 65,5 adet olmak üzere toplam 131 adet ergin sayılmıştır. Bu süre içinde tuzak başına yakalanan ergin sayısı esas alındığında ticari tuzak, H021 (465/6=77.5 adet), H006 (433/6=72.16 adet) ve N015 (628/6=104.6 adet) kodlu tuzakların gerisinde kalmıştır.

Örnekleme süresince kullanılan her renge ait 10 adet $(5$ renk x 2 tek.) tuzağın yerde $(0 \mathrm{~cm})$, $50 \mathrm{~cm}$ ve $110 \mathrm{~cm}$ yükseklikte topladığı ergin sayısı sirasılla toplam 662, 972 ve 622 adet olarak kaydedilmiştir. En fazla ergin (972 adet) ise $50 \mathrm{~cm}$ yükseklikteki tuzaklarda yakalanmıştır. Yerdeki (0 $\mathrm{cm})$ tuzakta toplam 662 adet ergin yakalanarak 2. sırada yer almıştır. Sonuç olarak her üç yükseklikte kullanılan 5 renge ait leğen tuzaklara farklı sayıda da olsa $T$. hirta ergini yakalanmıştır. Tüm tuzaklara erginlerin yakalanmasında cezbediciler etkili olmakla birlikte, tuzaklara yakalanan ergin sayısındaki farkın ise renk tonundan kaynaklandığ yüksekliklere göre farklı sayıda ergin yakalamıştır.

\section{Şeftali Bahçesinde Tropinota hirta Ergin Popülasyon Gelişmesi}

Şeftali bahçesinde örnekleme süresince kullanılan tüm leğen tuzaklara yakalanan toplam erginlerin örnekleme tarihlerine göre dağılımı, ağaçların çiçeklenme oranı (\%) ve iklim verileriyle ilişkisi Şekil 3'te verilmiştir. Şeftali ağaçları henüz çiçek açmadan 02.03.2019 tarihinde bahçeye yerleştirilen tüm tuzaklara ilk sayım tarihi olan 04 Mart'ta tuzak rengine ve yüksekliğine bakılmaksızın farklı sayılarda ergin yakalanmıştır. Vuts ve ark. (2012), E. hirta erginlerini yakalamada mavi renkli tuzakların başarılı olduğunu belirlemiştir. İlkbaharda meyve ağaçları yanında diğer bitkilerin çiçekleri ile de beslenen E. hirta'nın erginlerinin Afyon ilindeki kiraz ve elma bahçesinde 31 Mart'ta (Sağdaş 2011), Isparta'da kiraz bahçesinde 23 Mart'ta (Yaşar ve ark. 2013), Kahramanmaraş'ta badem bahçesinde ise 1 Mart tarihinde (Arslan ve Aslan 2015) tuzaklara yakalandığı bildirilmiştir. Görüldüğü üzere $T$. hirta erginlerinin ilk uçuş zamanı beslendiği meyve ağaçlarının çiçeklenme zamanıyla bağlantılı olarak da bölgelere göre değişiklik göstermiştir.

Örnekleme bahçesinde çiçeklenme 6 Mart'ta başlamış ve ergin sayısında görülen artış, 12-13 Mart tarihlerinde havanın yağışlı ve kapalı olmasıyla ile birlikte düşmüştür. Ancak, takip eden günlerde sıcaklıklardaki artışla bağlantılı olarak, şeftali ağaçlarında da çiçeklenme oranı artmış ve tuzaklara yakalanan ergin sayısı yeniden artmıştır. Tuzaklara yakalanan toplam ergin sayısı bahçede çiçeklenmenin \%100'e ulaştığ 18 Mart tarihinde toplam 562 âdet ergin ile en yüksek düzeye ulaşmıştır. Bu sayı örnekleme süresince tuzaklara yakalanan toplam erginlerin \%23.54'ne tekabül etmiştir. 22 Mart tarihinde havanın aşırı rüzgarlı olması erginlerin tuzaklara yakalanmasını olumsuz etkilemiş ve popülasyon eğrisinde ani bir düşme görülmüştür. Ayrıca 30 Mart'ta çiçeklenmenin sona ermesiyle de ergin sayısı azalmış, çiçeklenme sona ermesine (01.04.2019) rağmen, sayımlara devam edilmiştir. Nisan ayı boyunca düşük sayıda da olsa erginler tuzaklara yakalanmış 08 Nisan'da ve 1314 Nisan tarihlerinde havanın yağış̧ı olması nedeniyle ergin popülasyon gelişmesinde dalgalanmalar görülmüştür. Tuzaklara yakalanan ergin sayısındaki belirgin azalma ile 03.05.2019 tarihinde örnekleme sonlandırılmıştır. T. hirta ergin ergin popülasyon yoğunluğu mart ayında yüksek seviyede seyretmiş, ancak çiçeklenmenin sona ermesiyle nisan ayı boyunca ergin sayısı düşük düzeyde kalmıştır. 
Görüldüğ̈̈ üzere T. hirta erginlerinin şeftali bahçesindeki popülasyon yoğunluğu doğrudan ağaçların çiçeklenme (\%) yoğunluğu ile bağlantılı olduğu, ancak yă̆ış ve normalin üzerindeki kuvvetli rüzgarların ergin faaliyetlerini olumsuz etkilediği ve tuzaklara yakalanmada bir düşmeye neden olduğu gözlenmiştir. Buna karşın güneşli ve sıcak havalar da ise tuzaklara yakalanan ergin sayısı artmıştır. Nitekim Gezer ve Özpınar (2015) T. hirta erginlerinin leğen tuzaklara daha fazla yakalanmasını Çanakkale'nin rüzgarı ile bağlantılı olabileceği şeklinde ifade edilmiştir. Yaşar ve Dahham Dahham (2019) Isparta'da elma bahçelerinde kapalı ve yağışlı havalarda tuzaklara yakalanan ergin sayısının azaldığını bildirmiştir. Bunun yanında yapılan çalışmalarda ağaçların çiçek rengi ve yapısının erginlerin yakalanmasında etkili olduğu belirlenmiştir (Aydın, 2011). Diğer taraftan tarım alanları dışında erginlerin kışı geçirdiği yerler veya meraların konumu ile meyve bahçelerine olan yakınlığı ve erken ilkbaharda $T$. hirta erginlerinin ilk besin kaynağını oluşturan kolza gibi kültür bitkileri ile yabani hardal vb alanlardan meyve alanlarına olası geçişlerinde $T$. hirta ergin popülasyon yoğunluğunu etkileyebileceği kanısına varılmıştır.

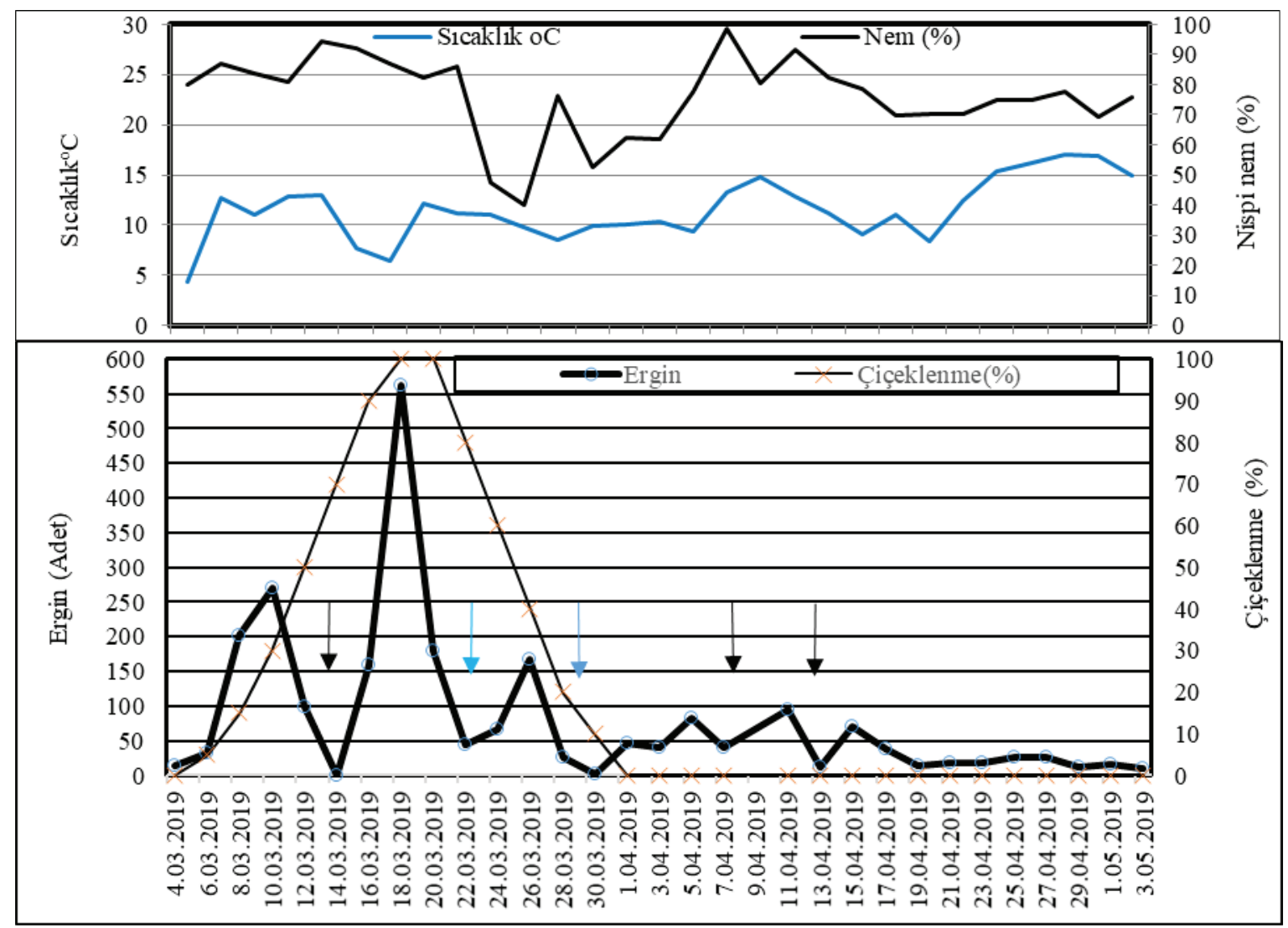

Şekil 3. Ezine (Çanakkale) ilçesi Akköy’deki şeftali bahçesindeki tuzaklara günlük yakalanan toplam Tropinota hirta ergin sayısının, iklim verileri ve çiçeklenme oranı $(\%)$ ile ilişkisi $\longrightarrow$ yağış; $\longrightarrow$ kuvvetli rüzgar )

\section{Tropinota hirta Erginlerini Yakalamada Tuzakların Karşılaştırılması}

Tropinota hirta erginlerini yakalamada kullanılan mavi rengin tonlarına ait H021, G021, H006, N015 ve Y157 kodlu tuzakların üç farklı yükseklikteki etkinlikleri değerlendirilmiş tuzaklara yakalanan ortalama ergin sayısı arasındaki farkın istatistiksel olarak önemli olduğu görülmüştür (Çizelge 2).

Yerdeki $(0 \mathrm{~cm})$ tuzaklarda tuzak başına günlük yakalanan ergin sayıları arasındaki fark istatistiksel olarak önemli bulunmuştur. N015 kodlu tuzak diğerlerinden farklı bir grupta yer almış ve yakaladığı günlük ortalama ergin sayısı $(4,10 \pm 1,14)$ diğerlerinden daha yüksek çıkmıştır. H021 kodlu tuzak ise günlük yakaladığı ergin sayısı 2,45 adet olup, 2. sırada yer almıştır. Yakaladığı ergin sayısı bakımında G021 kodlu tuzak farklı bir grupta yer almış olup, H006 ve Y157 koldu tuzak ile 
aralarındaki fark istatistiksel olarak önemsiz bulunmuştur.

Yerden $50 \mathrm{~cm}$ yükseklikte ise tüm tuzaklara yakalanan ergin sayıları arasındaki fark önemsiz çıkmıştır. Ancak, en fazla günlük ortalama ergin sayısı N015 kodlu tuzakta kaydedilmiştir. Yerden $110 \mathrm{~cm}$ yükseklikteki tuzaklarda ise H006 kodlu tuzakta yakalanan ergin sayısı istatistiksel olarak diğerleri (H021, G021, N015) ile aynı grupta yer almasına karşın daha fazla ergin yakalandığı görülmüştür. En düşük ergin sayısı Y157 kodlu tuzakta kaydedilmiştir.

Çizelge 2. Mavi rengin 5 farklı tonundaki tuzaklara $(\mathrm{F}=10,466 ; \mathrm{df}=4)^{*}$ üç yükseklikte $(\mathrm{F}=7,258, \mathrm{df}=2)^{* *}$ yakalanan ergin sayılarının karşılaştırılması (Ort. \pm S.H.; $\mathrm{P}<0,05 ; \mathrm{n}=30$ örnekleme sayısı)

\begin{tabular}{|c|c|c|c|}
\hline Tuzak kodu* & $0 \mathrm{~cm}^{* *}$ & $50 \mathrm{~cm}^{* *}$ & $110 \mathrm{~cm} * *$ \\
\hline $\mathrm{H} 021$ & $\begin{array}{c}2,45 \pm 0,62 \mathbf{A} \\
\text { b }\end{array}$ & $\begin{array}{c}3,25 \pm 0,86 \mathbf{A} \\
\mathbf{a}\end{array}$ & $\begin{array}{c}2,05 \pm 0,59 \mathbf{A} \\
\mathbf{a b}\end{array}$ \\
\hline G021 & $\begin{array}{c}1,27 \pm 0,32 \mathbf{A} \\
\mathbf{c}\end{array}$ & $\begin{array}{c}2,57 \pm 0,73 \mathbf{A} \\
\mathbf{a}\end{array}$ & $\begin{array}{c}2,22 \pm 0,71 \mathbf{A} \\
\mathbf{a b}\end{array}$ \\
\hline H006 & $\begin{array}{c}1,38 \pm 0,27 \mathbf{A} \\
\mathbf{b c}\end{array}$ & $\begin{array}{c}3,07 \pm 0,90 \mathbf{A} \\
\mathbf{a}\end{array}$ & $\begin{array}{c}2,77 \pm 0,63 \mathbf{A} \\
\mathbf{a}\end{array}$ \\
\hline N015 & $\begin{array}{c}4,10 \pm 1,14 \mathbf{A} \\
\mathbf{a}\end{array}$ & $\begin{array}{c}4,37 \pm, 1,32 \mathbf{A} \\
\mathbf{a}\end{array}$ & $\begin{array}{c}2,00 \pm 0,68 \mathbf{B} \\
\mathbf{a b}\end{array}$ \\
\hline Y157 & $\begin{array}{c}1,83 \pm 0,44 \mathbf{A B} \\
\mathbf{b c}\end{array}$ & $\begin{array}{c}2,95 \pm 0,98 \mathbf{A} \\
\mathbf{a}\end{array}$ & $\begin{array}{c}1,33 \pm 0,42 \mathbf{B} \\
\mathbf{b}\end{array}$ \\
\hline
\end{tabular}

Tuzakların üç farklı yükseklikte yakaladığı ergin sayısı karşılaştırıldığında; H021, G021 ve H006 kodlu tuzakların yakaladığı günlük ergin sayısı arasındaki fark önemsiz çıkmıştır. N015 kodlu tuzak yerde $(0 \mathrm{~cm})$ ve $50 \mathrm{~cm}$ ' de yakaladığı günlük ortalama ergin sayısı arasındaki fark önemsiz olup, yerde ortalama 4,10 ve $50 \mathrm{~cm}$ de ortalama 4,37 adet ile en yüksek sayıda ergin kaydedilmiştir. Y157 kodlu tuzak ise en fazla ergin $50 \mathrm{~cm}$ yükseklikteki tuzaklarda yakalanmış, ancak $0 \mathrm{~cm}$ 'de yakalanan ergin sayısıyla aralarındaki fark önemsiz bulunmuştur. Yerdeki tuzakta yakalanan ergin sayısıyla 110 cm'de yakalanan ergin sayısı arasında istatistiksel fark önemsiz çıkmıştır.

Kullanılan mavi rengin 5 farklı tonundaki cezbedici ekli içinde su bulunan leğen tuzaklara 0 $\mathrm{cm}$ (yerde), $50 \mathrm{~cm}$ ve $110 \mathrm{~cm}$ yüksekliğinde farklı sayı da $T$. hirta ergini yakalanmıştır. En fazla ergin N015 kodlu tuzakta ve $50 \mathrm{~cm}$ de sayılmıştır. Aynı kodlu tuzak yerde de en iyi sonucu sağlamıştır. Dolayısıyla yerden $50 \mathrm{~cm}$ yükseklikteki tuzakların yerleştirildiği sehpa maliyeti göz önüne alındığında üretici koşullarında yerdeki tuzakların önerilmesinin uygun olacağ kanısına varılmıştır.

Şeftalinin çiçeklenme periyodunda farklı yüksekliklerde tuzaklara yakalanan ergin sayıları örnekleme tarihlerine göre grafik haline getirilmiştir (Şekil 4). Tuzaklara yakalanan ergin sayıları birbirinden farklı olmakla birlikte popülasyondaki dalgalanmalar benzerlik göstermiştir. Çiçeklenmenin \%100'e ulaştığı Mart ayının ortalarında yakalanan ergin sayısı tüm tuzaklarda en yüksek düzeye ulaşmıştır. Yüksekliklere göre tuzaklara yakalanan ergin sayısı incelendiğinde tüm tuzaklarda $50 \mathrm{~cm}$ de ergin sayısı en yüksek seviye ulaşmıştır. G021 ve H021 kodlu tuzaklar ise $110 \mathrm{~cm}$ yükseklikte benzer etkiyi görülmüştür. N015 ve H021 kodlu tuzaklarda yakalanan ergin sayısı ise 0 $\mathrm{cm}$ de benzer durumu göstermiştir.

Tuzaklara erginler yakalandıktan sonra çiçeklenmenin sona erdiği 30 Mart tarihine kadarki dönemde yakalanan ergin sayısı toplam ergin sayısıyla oransal olarak karşılaştırıldığında; aralarında önemli bir fark olmadığ 1 görülmüştür. Ticari tuzakta yakalanan erginlerin \%72,51'i 30 Mart tarihine kadarki dönemde toplanmıştır. H006 kodlu tuzakta ise $0 \mathrm{~cm}, 50 \mathrm{~cm}$ ve $110 \mathrm{~cm}$ yükseklikte sirasıyla erginlerin $\% 68,67, \% 79,89$ ve \%62,04'ü bu dönemde tuzaklara yakalanmıştır. Y157 kodlu tuzaklara yakalanan ergin sayısının oranı \%77,27, \%80,79 ve \%82,50 şeklinde gerçekleşmiştir. N015 kodlu tuzakta aynı dönemde yakalanan ergin oranı yüksekliklere göre $\% 76,82, \% 83,20$ ve $\% 66,66$ olarak gerçekleşmiştir. G021 kodlu tuzaklarda ise 30 Mart tarihine kadar sırasıyla erginlerin \%78,94'ü, $\% 79,87$ 'si ve $\% 81,20$ 'si tuzaklarda toplanmıştır. H021 kodlu tuzaklarda ise bu oran \%79,59, \%75,89 ve $\% 67,47$ şeklindedir. Çiçeklenmenin sona erdiği 30 Mart tarihine kadar yakalanan erginlerin toplam sayıya oranına $110 \mathrm{~cm}$ de Y157 ve G021 kodlu tuzaklarda yüksek iken, diğerlerinden düşük kalmıştır. $\mathrm{Bu}$ durumun tuzak renginden kaynaklı olabileceği düşünülmüştür. 
ÇOMÜ Zir. Fak. Derg. (COMU J. Agric. Fac.)

2019: 7 (2): 239-247

ISSN: 2147-8384 / e-ISSN: 2564-6826

doi: 10.33202/comuagri.620590

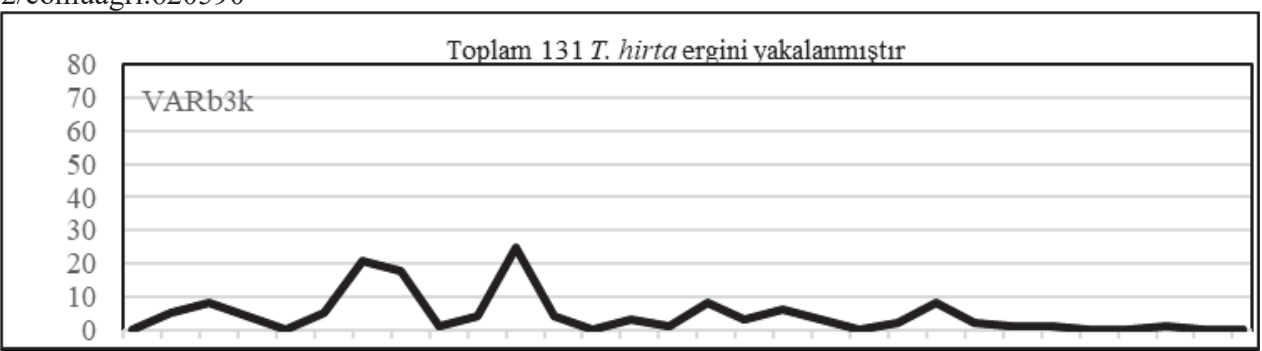

Toplam (0 cm'de 147, 50 cm'de 195 ve 110 cm'de 123) 465 T. hirta ergini yakalanmıştır
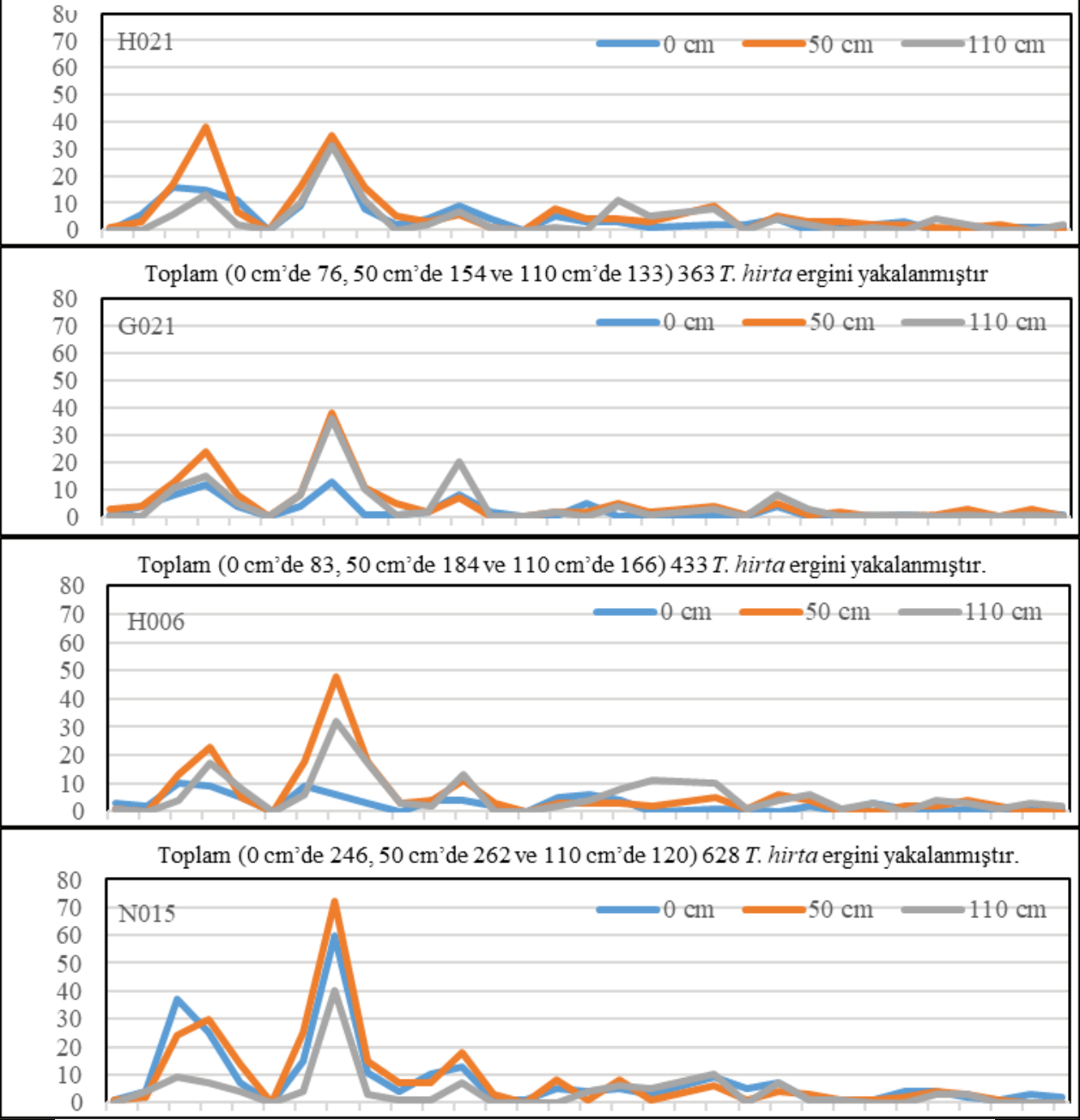

Toplam (0 cm'de 110, 50 cm'de 177ve 110 cm'de 80) 367 T. hirta ergini yakalanmıștır.

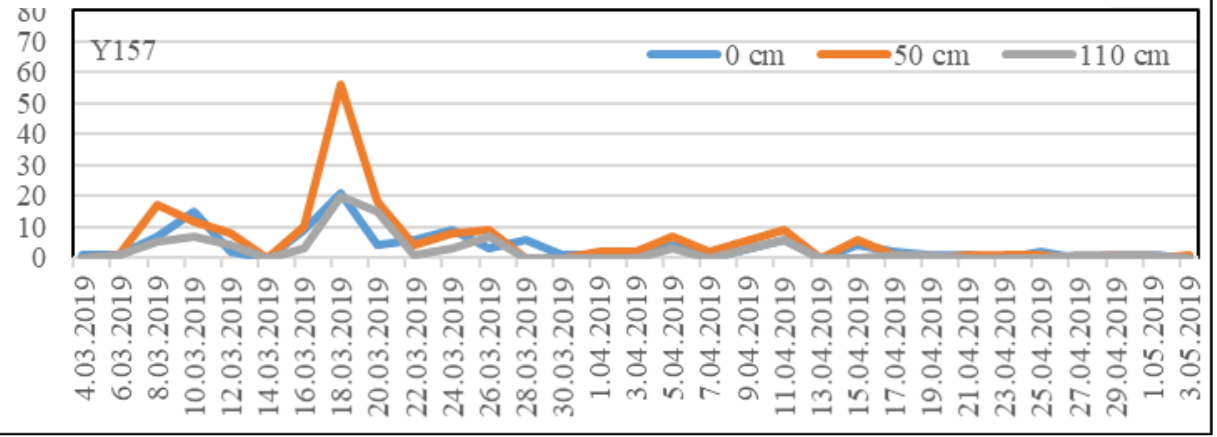

Şekil 4. Ezine (Çanakkale) ilçesi Akköy'de şeftali bahçesinde farklı renk tuzaklara $0 \mathrm{~cm}, 50 \mathrm{~cm}$ ve $110 \mathrm{~cm}$ yükseklikte yakalanan Tropinota hirta erginlerine ait popülasyon eğrileri 


\section{Sonuç ve Öneriler}

Sonuç olarak bu çalışmada incelenen mavi rengin 5 farklı tonuna ait cezbedici ilave edilmiş içinde su bulunan leğen tuzaklar yerde $(0 \mathrm{~cm}), 50$ ve $110 \mathrm{~cm}$ 'de $T$. hirta erginlerini yakalamada başarılı olmuştur. Tüm tuzaklar ergin popülasyon yoğunluğunun yüksek olduğu çiçeklenme döneminde ve çiçeklenme sonrası düşük ergin yoğunluğunda da benzer etkiyi göstermiştir. Dolaysıyla incelenen renkler içinde N015 kodlu leğen tuzaklarda en fazla ergin yakalamıştır. Bunu H021 kodlu tuzak izlemiştir. Diğer taraftan $T$. hirta erginleri en fazla $50 \mathrm{~cm}$ yükseklikteki tuzaklara yakalanmıştır. $\mathrm{Bu}$ tuzakları yerdeki tuzaklar izlemiştir. Şeftali bahçesinde yakalanan T. hirta erginlerinin \%20-35'nin çiçeklenme sonrası döneme ait olması bu zararlı ile mücadele periyodunun belirlenmesinde dikkate alınması gereği ortaya çıkmıştır. Bu durumun şeftali bahçesi dışındaki diğer alanlardaki erginlerin varlığından kaynaklanabileceği kanısını uyandırmıştır. Nitekim araştırma alanına yakın bir kiraz bahçesinde yapılan gözlemlerde bu durum teyit edilmiştir. Zira Mitko ve ark. (2011) T.hirta ergin uçuşlarının mart ayında başlayarak temmuz ayı ortalarına kadar devam ettiğini tespit etmiştir. Özellikle Çanakkale koşullarında iç içe tesis edilen veya bitişik bahçelerdeki meyve alanlarında ergin varlığının uzun süre devamı için uygun ortamın varlığı bu zararlı ile mücadelede dikkate alınmalıdır. Popülasyondaki genel dalgalanmaların ise büyük oranda yağış ve aşırı rüzgârlı dönemlerde yakalanan ergin sayısındaki azalmalar ve artan sıcaklık ile açık havada tuzaklara yakalanan ergin sayısındaki artışla ortaya çıktığı görülmüştür. Açık ve güneşli havaların hakim olduğu dönemlerde bu zararlının zarar yapma potansiyeli artacaktır. Diğer taraftan bu çalışmada $50 \mathrm{~cm}$ yüksekliğindeki tuzaklara daha fazla ergin yakalanmıştır. Tuzak yüksekliği için sehpa maliyeti göz önüne alındığında, yerdeki tuzakların da bu zararlı için önerilebileceği kanısına varılmıştır. Meyve yetiştiriciliğinin yaygın olduğu Çanakkale ilinde üreticilerle yapılan görüşmede şeftali alanlarında $T$. hirta ergin yoğunluğu yüksek olmasına karşın verecekleri zararın meyve seyrelmeden dolayı önemsenmediği bildirilmiştir. Meyve alanlarının içe içe veya birlikte tesis edildiği Çanakkale'de şeftali alanlarında yüksek yoğunluğa ulaşan bu zararlıya karşı gerekli önlemin alınmaması kiraz alanlarındaki başarıyı olumsuz etkileyecektir. Dolayasıyla ilkbaharda erken çiçek açan şeftali ve benzeri alanların kontrol altında tutulması diğer meyve alanlarında zararlı ile mücadeledeki başarıyı arttıracaktır.

\section{Teşekkür}

Çalışmanın yürütülmesi için bahçelerini bize açan üreticiye, tuzaklarda kullanılan cezbedicilerin sağlanmasında desteğini esirgemeyen, Kapar Organik Tarım Sanayi Ticaret Ltd. Şti.’ne teşekkürü borç biliriz.

Not: Bu çalışma Çanakkale Onsekiz Mart Üniversitesi, Fen Bilimleri Enstitüsü, Bitki Koruma Anabilim Dalında 22.08.2019 tarihinde tamamlanan İbrahim ERBAY'ın yüksek lisans tezinden üretilmiştir.

\section{Kaynaklar}

Arslan Ö. M., Aslan M. M., 2015. Kahramanmaraş İli Badem Ağaçlarında Bakla Zınnı (Epicometis hirta (Poda, 1761)) (Coleoptera: Scarabaeidae)'nın Farklı Tuzaklarla Yakalanması Üzerine Araştırma. Kahramanmaraş Sütçü İmam University Journal of Natural Sciences, 18 (4): 6-12.

Aydın G., 2011. Plant Phenology-Related Shifts in Color Preferences of Epicometis (Tropinota) hirta (Coleoptera: Scarabaeidae: Cetoniinae) Adults-Key to Effective Population Monitoring and Suppression. Florida Entomologist, 94 (4): 832-838.

Aydın G., Yaşar B., 2019. Comparison of color and attractant traps effect used for sampling apple blossom beetle (Tropinota hirta (poda, 1761) (Coleoptera, Scarabaeidae; Cetoniinae)). Applied Ecology and Environmental Research, 17(4), 7453-7462.

Ercan Ş., Özpınar A., 2014. Çanakkale İlinde Archips rosana (Linnaeus, 1758) ve Pandemis cerasana (Hübner,1786) (Lepidoptera: Tortricidae)'nın Meyve Alanlarında Yayılışı Ve Şeftali Bahçelerinde Popülasyon Gelişmesi. Bitki Koruma Bülteni, 54: 267-281.

Ertop S., Özpınar A., 2011 Çanakkale İli Kiraz Ağaçlarındaki Fitofag ve Yazarlı Türler İle Bazı Önemli Zararlıların Popülasyon Değiş̧imi. Türkiye Entomoloji Bülteni, 1: 109-118

Gezer B., Özpınar A., 2015. Çanakkale İlinde Şeftali, Elma, Kiraz ve Kayısılarda Tropinota hirta (Poda) (Coleoptera:Cetoniidae) Ergin Yoğunluğunu Belirlemede Farklı Tuzakların Değerlendirilmesi. Çanakkale Onsekiz Mart Üniversitesi, Zir. Fak. Derg., 3(2):27-34.

Güvenç C., Yaşar B., 2014. Mavi Renkli Huni Tuzaklarda Kullanılan Farklı Cezbedicilerin Kiraz Çiçeklerinde Beslenen Tropinota hirta (Poda) (Coleoptera: Scarabaeidae) Erginlerinin Yakalanması Üzerine Etkisi. Süleyman Demirel University, Journal of Natural and Applied Science, 18(3): 97-104.

IBM, 2015. IBM Corp. Released 2015, IBM SPSS Statistics for Windows, Version 23.0. 
Kara K., 1992. Tropinata hirta (Poda) (Coleoptera: Scarabaiidae)'nın Tokat ve Çevresindeki Konukçuları, Yayılışı, Zarar Düzeyi, Bazı Biyolojik Özellikleri ve Mücadele İmkanları Üzerinde Araştırmalar. Cumhuriyet Üniversitesi, Fen Bilimleri Enstitüsü (Basılmamış) Yüksek Lisans Tezi, Tokat, 37 S.

Kutinkova H., Andreev R., 2004. Integrated Pest Management in Sweet Cherry (Prunus avium L.) Orchards in Bulgaria. Journal of Fruit and Ornamental Plant Research, 12: 41-47.

Mitko A. S., Teodora B. T., Radoslav A. A., Vilina D. P., Vasilina D. M., Teodora S. S., Nikolina T. M., Petko M. M., Dimitar I. V., 2011. Employing Floral Baited Traps for Detection and Seasonal Monitoring of Tropinota (Epicometis) hirta (Poda) (Coleoptera: Cetoniidae) in Bulgaria. Acta Zoologica Bulgarica, 63 (3): 269-276.

Oltean I., Macavei L. I., Vasian I., Tötös, S. Varga M.,Florian T., 2015. Use of Semiochemical Products in Monitoring and Control of Epicometis hirta Poda. Bulletin USAMV series Agriculture 72(2)/2015, DOI 10.15835 .

Özbek H., 2008 Türkiye'de Ilıman İklim Meyve Türlerini Ziyaret Eden Böcek Türleri. Uludağ Arıcılık Dergisi, 8(3): 92-103.

Özpınar A., Şahin A.K., Polat B., Özbek İ. 2012. Çanakkale ili meyve alanlarında Grapholita molesta (Lepidoptera: Tortricidae)'nın yayılıșı ve ergin popülasyon değişimi. Bitki Koruma Bülteni, 52:71-80.

Özpınar A., Özbek İ., Şahin A. K. , 2014. Adult population fluctuation of Oriental fruit moth, Grapholita molesta (Lep.: Tortricidae) in peach orchards of Çanakkale, Turkey. Journal of Entomological Society of Iran, 34 (3): 1-8.

Özpınar A., Uçar Ö., 2018. Çanakkale İlinde Anarsia lineatella Zeller Lepidoptera: Gelechiidae)'nın Popülasyon Gelişmesi ve Mücadelesinde Çiftleşmeyi Engelleme Tekniğinin Kullanım Olanağının Araştırılması. ÇOMÜ Zir. Fak. Derg. (COMU J. Agric. Fac.) 6 (1): 41-49.

Sağdaş A., 2011. Farklı Tuzakların Afyonkarahisar İli Sultandağı İlçesinde Kiraz ve Elmalarda Zarar Yapan Baklazınnı (Epicometis (Tropinata) hirta Poda Coleoptera: Scarabaeidae))'nın Yakalanması Üzerine Etkisi. Süleyman Demirel Üniversitesi F.B.E Bitki Koruma A.B.D. Yüksek Lisans Tezi Isparta, 162 S.

Schmera D., Toth M., Subchev M., Sredkov I., Szarukan I., Jermy T., Szentesi A., 2004. Importance of Visual and Chemical Cues in the Development of an Attractant Trap For Epicometis (Tropinota) hirta Poda (Coleoptera: Scarabaeidae). Crop Projection, 23 (10): 939-944.

Şahin A.K., 2018. Çanakkale ilinde farklı meyve türlerinde Doğu meyvegüvesi (Grapholita molesta Busck., (Lepidoptera; Tortricidae)'nin biyo-ekolojisi üzerinde araştırmalar. ÇOMU Fen Bilimleri Enstitüsü, Yayınlanmamış Doktora Tezi; $85 \mathrm{~S}$.

TUIK, 2018. Bitkisel Üretim İstatistikleri. http://tuikapp.tuik.gov.tr/bitkiselapp/bitkisel.zul. (Erişim Tarihi:15 Haziran 2019).

Vuts J., Razov J., Kaydan M. B., Tóth M., 2012. Visual and Olfactory Cues for Catching Parasitic Wasps (Hymenoptera: Scoliidae). Acta Zoologica Academiae Scientiarum Hungaricae 58 (4): 351-359.

Yaşar B., Çeşme İ., Baydar M. S., Aysal İ., Yazır A. B., 2013. Farklı Mavi Renkli Huni Tuzaklarının Kiraz Ağaçları Çiçeklerinde Beslenen Bakla Zınnı [Epicometis hirta (Poda) (Coleoptera: Scarabaeidae)]'nın Yakalanması Üzerine Etkisi. Türkiye Entomoloji Dergisi, 3(2): 99-105.

Yaşar B., Uysal O., 2013. Evaluation of the Efficacy of Different Traps in Capturing Apple Blossom Beetle (Tropinota hirta (Poda, 1761)) (Coleoptera: Scarabaeidae). Türkiye Entomoloji Dergisi, 37 (2): 169177.

Yaşar B., Dahham Dahham O. A., 2019 Farklı Elma Çeşitleri Üzerine Asılan Tuzakların Tropinota hirta (Poda, 1761) (Coleoptera: Cetoniidae)'nın Yakalaması Üzerine Etkisi Turkish Journal of Agricultural Research 6(1): 57-64. 